\title{
Integrating Educational Technologies to Augment Learners' Academic Achievements
}

\author{
https://doi.org/10.3991/ijet.v15i02.11809 \\ Preeti Jaiswal \\ University of Bahrain, Sakhir, Kingdom of Bahrain \\ pjaiswal@uob.edu.bh
}

\begin{abstract}
Considering the manner in which technology is proliferating in all spheres of life, it is becoming pivotal to use Information and Communication Technology (ICT) in teaching and learning process, in today's information age classrooms, by implementing digital learning tools. The purpose of this study is to determine the consequences of technological implementation on students' academic achievements, in higher education. A mixed method, qualitative and quantitative, was used to collect data. A total of 40 students studying the course entitled English for Business in Department of English Language \& Literature, College of Arts, during the academic year 2017-18 at University of Bahrain participated in this study. The findings obtained from the quantitative evaluation and qualitative dimensions of the study revealed that the course educators and students had a positive attitude towards the use of educational technologies as it impacted students' performances positively.
\end{abstract}

Keywords-Educational technologies, Learning management system, gamification of learning, digital instructional strategies

\section{$1 \quad$ Introduction}

Recently, educators in higher educational institutions are facing the challenges of teaching large sized classes with mixed ability groups. Implementing educational technologies in classroom teaching could offer solutions to this situation, as the free, blended learning platform provides a number of advantages for both students and educators and caters to all types of learning styles and different cognitive levels. Easy access to online resources on subjects enhances the awareness of learners, motivates them in adopting different e-learning strategies and helps them to build higher order thinking and creativity skills while constructing knowledge. Learners can learn useful life skills through technology and foster a number of practical skills, such as creating presentations, learning to draw distinctions between reliable and unreliable sources on the Internet and maintaining proper online etiquette. Students can practice collaborative skills by getting involved in different online activities It is proven that learners, who are engaged, interested in and understand the relevance of content they are studying, are expected to have better knowledge retention Likewise, by incorporating edu- 
cational technologies into classroom teaching, educators can enhance the traditional strategies of teaching and engage students in active learning activities. By using online assessments tools and multimedia, educators can save time which can be used for assisting students at risk and for promoting a better communication system with their students, one that extends beyond the walls of the classroom. Effective communication is regarded as a key component of an engaged and successful class. Keeping these advantages in mind, I used digital technologies to augment the teaching learning process in six ways: by using Blackboard Learn as a learning management system (LMS), adopting game based pedagogies, applying digital multimedia into classroom teaching, integrating web based online assignment submission system, incorporating social media for collaborative learning, working with Google Tools to engage students and utilizing Optical Mark Recognition(OMR) test analysis reports for assessments of students' performance.

\subsection{Material studied}

Considering the manner in which technology is proliferating in all spheres of life, it is becoming pivotal to use Information and Communication Technology (ICT) in teaching and learning process, in today's information age classrooms, by implementing digital learning tools, such as computers, laptops, tablets and mobiles to expand course curriculum, make teaching and learning more meaningful and fun, build 21 st century skills and enhance students' active participation in the learning process. Educational technology is a systematic process of applying current technology to foster the quality of education. Some useful educational technologies that can be used to augment teaching learning process include: using Blackboard Learn as a learning management system (LMS), adopting game based pedagogies, applying digital multimedia into classroom teaching, integrating web based online assignment, incorporating social media for collaborative learning, working with Google Tools to engage students and utilizing OMR test analysis reports for assessments. "Blackboard-learn" $(\mathrm{Bb})$ is a set of software tools designed for dispensing online teaching and learning in Higher Educational Institutions (HEI) (Hall, 2001). It is a web-based system that assists educators with a better way to plan, design and deliver content, monitor and assess students' performance (Blackboard, 1997-2011). Currently, gamification, an important aspect of technology-infused education, is being viewed as an innovation to foster active engagement of students and enrich students' learning experiences. The multi-sensory, experiential nature of game-based student response system promotes learners' critical thinking and problem-solving skills (McFarlane, Sparrowhawk, \& Heald, 2002). As they are required to answer all questions in order to advance to the "next level" According to (Papastergiou, 2009) game-based student response systems(GSRS) like mobile device teaching tools, require learners to activate prior knowledge, and assess their accomplishments while they are playing and learning taught content. (Rosas et al., (2003) proposes that GSRS for example Kahoot, enhances positive classroom dynamics and improve students' interactions with their peers and lecturers. Many educators support the transition from using traditional tools in teaching to incorporating multimedia tools like presentation slide shows, audio tracks 
and video clips to motivate interest and enrich class engagement and enhance understanding of course material. The emotions which are created by specific visual scenes, actors and music saves a powerful effect on their mind and senses (Berk, (2009). Many educators have begun to incorporate videos and multimedia presentations in their classes as they are an efficient and effective way to reach their students. Berk (2009, p3) mentioned 20 learning outcomes related to using videos in the classroom.

In this digital era, where information is readily accessible from anywhere and at any time, a web based online submission is posing potential benefits for the teaching learning process. The educational use of the Internet in providing online homework and supplementary worksheets to reinforce taught concepts is growing rapidly. Tregobov breaks the process down into four stages: submission, recording, marking, and return. Some researchers suggest that electronic homework as a course element has more positive effects than written homework (Dufresne, Mestre, Hart, and Rath (2002); Ogilve, (2000); Thoennessen and Harrison, (1996). For example, Dufresne et al., (2002) compared the effect of electronic homework and written homework on student achievement and found that electronic homework led to higher overall exam performance. Recently, Higher education is gauging the benefits of using social media in teaching and learning. According to Bercovici (2010), students use social media in general for the purpose of interactive engagement in the social environment. Some researchers like Larusson and Alterman, (2009), Ertmer et al., (2011) emphasize on the positive influence of social media on the process of learning leading to a better level of performance. For instance, Junco et al. (2011) investigated the utilization of Twitter and Blogs while Novak et al., (2012) studied the benefits of different types of social media. They all came to a common agreement that these tools play a significant role in fostering the performance of learners and promoting active collaborative learning at the level of higher education. Google Apps are useful for learner-centred environments. It enables learners to create groups and work collaboratively in teams. It broadens learners' knowledge by making accessible a plethora of infinite resources. Additionally, Google Sites provide educators an affordable, easy to manage tool for designing and sharing supplementary worksheets without having knowledge of HTML or any other programming language (Google, (2015); Mansour, (2012). Technology paves the way for a change in role of the teacher from being just a disseminator of information to being a facilitator in the learning coaching process and supporting learners as they explore and share the available information. The web-based platform of Google enables anywhere, anytime accessibility and is evolving as a new learning paradigm for learner-centred environments. It enables learners to create groups and work cooperatively. Likewise, OMR technology has changed much in recent years in higher education. OMR is very beneficial when a large volume of data must be compiled and processed within a short period of time. Many educators prefer exams being conducted using OMR bubble answer sheets as with this technology the conduction of exam is objective, accurate, easier and much faster. The study attempts to answer the following research question: Does incorporating educational technologies into teaching learning process boost students' academic performance? 


\subsection{Implementing educational technologies in teaching learning processes}

Using blackboard learn as a Learning Management System (LMS): What is it? Educators may find Blackboard Learn useful as a course management system that provides an effective virtual learning environment to students. The blackboard homepage displays the different features of the LMS system such as course catalogue, course calendar, course tools, announcements, and built in anti-plagiarism service (Turnitin).How does it foster teaching learning process? It was very convenient to upload course syllabus, power point presentations, quizzes, supplementary worksheets, results on a common learning platform. Students could retrieve all course related material at a central location. There was symmetry of handouts as students from all sections were using same handouts online, and there were plenty of easily accessible worksheets to reinforce their learning anytime and anywhere as long as they were connected to the internet. They could get instant constructive feedback, and check their grades electronically and monitor their progression in learning. This encouraged reflective thinking. Blackboard learn may give educators and students potential benefits like increased availability, quick feedback, improved two-way interactions, tracking, and building skills such as organization, time management and communication (Bradford et al., (2007).Users always access blackboard learn through the internet anytime and anywhere (DeNeui \& Dodge, (2006)

Adopting gamification of learning: What is it? The gamification of learning is an educational approach to motivate students to learn by using game elements in learning environments. How does it foster teaching learning process? Kahoot is a game-based classroom response system launched in 2013. This platform offers educators engaging ways to test learners by creating a collaborative, competitive, fun and game-like environment in the classroom. The educators display questions on a shared screen, while students singly or in teams answer those questions using any device smartphones, tablet or computer. The learning approach encourages "self-directed learning", where learners takes ownership over their learning process. With the device in hand, learners feel empowered to actively participate instead of being passive listeners as in traditional lecture style. According to Bransford, Brown, and Cocking (1999) "assessments and feedback must focus on understanding, (and) assessments that emphasize understanding do not necessarily require elaborate or complicated assessment procedures. Even multiple-choice tests can be organized in ways that assess understanding" (140). This educational technology also comes in handy when educators are in need of a few -minute's filler.

Applying digital multimedia in classroom: What is it? Multimedia refers to interactive, computer-based applications that combine five basic types of media: audio, video, text, animation, and graphics. The ability of computers to offer real-time illustrations of almost all kinds of media and sensory modes of instruction are generally referred to as Multimedia (Clark, (2005).How does it foster teaching learning process? By implementing multimedia in the classroom educators can engage students in active learning and it helps in better retention of information. Educators can use a variety of multimedia tools in their classrooms to appeal to all learning styles. A song with an easily repeated chorus can be used as a warm up or nice lead-in to the lesson. 
Songs can also serve as a springboard for discussing a specific grammar point by asking learners to look through the lyrics and find examples of a grammar structure or as a powerful tool in teaching new vocabulary. Additionally, video can add a new dimension to aural practice in the classroom. The dialogues, gestures, setting, action, emotions in the video clip, provide a vital visual stimulus for language production and practice. Furthermore, slide presentation software like PowerPoint is becoming an indigenous tool of many instructional settings, particularly in large classes. They allow for more sensory stimulation through the incorporation of many tools in one electronic slide show such as videos files, speech, text, music files, and images and appeals more to the human senses. Microsoft PowerPoint allows not only educators to have greater flexibility in presenting lessons, which can be used innumerable times and modified according to different classes learning requirements but also lets learners take the helm. Students can be encouraged to make short presentations. Such active learning tasks stretch students' creativity, and the practice of speaking in front of a classroom helps them develop communication skills. According to (Atkins-Sayre, Hopkins, Mohundro, and Sayre, (1998) PowerPoint software is one of the "most prevalent types of technology being used in the classroom" for more sensory stimulation.

Integrating web based online assignment submission system: What is it? The submission of an assignment online is an easy method for learners and educators. It gives the ability to learners to submit allotted tasks from any place served by internet and instructors the scope to create automated assessment to evaluate the students' work online and monitor their progress easily. How does it foster teaching learning process? According to Arasasingham, Martorell and McIntire (2011), online homework "can be engaging to students, present opportunities for self-directed study to learn the desired material, provide effective feedback and supply a range of opportunities for practice" (p. 78). It is also seen, that completing homework within deadlines, helps students learn time management skills, builds self-esteem and makes them more responsible.

Incorporating social media for collaborative learning: What is it? Rouse \& Wigmor (2015) suggest that social media enables users to create and share content with each other.They assist users in creating, maintaining and organizing discussions with others (ibid). How does it foster teaching learning process? The increasingly popular types of social media like WhatsApp, Facebook, Instragram and Snapchat, are being seen as having great potentialities to increase social interaction among studentstudent and student-teacher. WhatsApp is simple and free, unlimited mobile messaging app that can be used to facilitate real-time communication between learners and instructors. Students are well versed in using this popular social media to communicate with each other and share messages either through screenshots or by forwarding media. WhatsApp study groups can be formed to encourage collaboration. Educators can use the group chat as a forum to provide opportunities for extended learning outside the classroom. Students who are shy can use this digitized environment to clarify queries. According to (Bouhnik and Deshen, (2014) WhatsApp in learning has four main purposes: communicating with students, building a social atmosphere, creating dialogue, and encouraging students to share. 
Working with Google tools to engage students: What is it? Google Docs is a web based application which is completely free. It allows educators to create, edit and store text documents, spreadsheets, questionnaires and slide presentations online and centralize them under one domain. It allows real-time collaboration from diverse locations. How does it foster teaching learning process? Some Google applications that educators may find useful are: Google drive as cloud storage is accessible at a centralized domain allowing real-time collaboration and multiple viewing/editing features, Google Sheets for listing student names and grades, Google Forms for surveys, questionnaires, summary of results, data collection, Google Calendar for preparing pacing schedule, highlighting exams and test dates and deadlines of assignments, YouTube for enhancing course content. These collaborative tools enable educators to shared supplementary worksheets and the online component reduces extraneous printing of worksheets.

Utilizing OMR test analysis reports for assessments: What is it? Invented by Michael Sokolski, Optical Mark reading (OMR) is an automated method, by which the optical mark readers read pencil or pen marks indicated in pre-determined positions on "fill-in-the-bubble" scanned sheets, as responses for multiple choice tests and enters data input into the computer system, which evaluates the data and stores the result in a user friendly spreadsheet. This information recognition technology has been widely used in education since the 1960s and is particularly useful when data from large numbers of hand-filled forms are required to be processed quickly. How does it foster teaching learning process? Assessment of the recent large class sizes poses a real challenge. In such situations, Optical Mark Recognition is an easy and convenient solution for standardized testing. Students can be provided standard multiple choice tests in which they record their answers on a bubble sheet designed for OMR. The forms can then be scanned and the results are computed using a standard office application. The analyzed results can either be stored online or exported in the form of excel sheet format. This information recognition technology uses a fair method of assessment, as testing is objective , and is therefore an efficient, accurate means of conducting any examination. It allows very fast processing and the results can be delivered within a day. The test analysis gives educators details regarding students' achievements in relation to the intended learning outcomes. This helps educators improvise their teaching learning pedagogies and instructional strategies according to students' strength and weakness. Likewise, it gives prompt, individualized, specific and relevant feedback to learners. It is paramount for learners to know how well they are doing while they are learning as it guides them in their learning process and gives them the direction they need to reach the goal of the lesson.

\subsection{Methods}

A qualitative focus group study was conducted as well as quantitative method was used to find out if there was a significant difference between students' performance in an exam before and after implementing educational technologies in the teaching learning process. 
Sample: The sample consisted of 7 course educators and 40 students (19 males and 21 females) who were studying the course entitled English for Business in Department of English Language \& Literature, College of Arts, during the academic year 2017-18 at University of Bahrain. The course emphasizes on enhancing students' reading and writing skills in English so that they can comprehend English business texts, and use business specialist vocabulary with increased confidence as well as use discourse functions encountered in a business administration environment to produce business correspondence of various types.

Instrument: Qualitative analysis from two surveys and classroom observations, during the academic year were collected and analyzed to examine in-depth the perceptions of both students and teachers about the introduction of digital technologies during teaching and learning practices. One survey was given to course educators to evaluate their perceptions regarding incorporating technology in classroom teaching and the other survey was given to forty students studying the course to understand their viewpoints regarding this implementation. In addition, Pre- and post-tests were used to collect data about students' academic accomplishment before and after implementing educational technologies into teaching learning process. Pretest was given on March 21 and the post test was given on May 30. The analytical test comprised of questions in multiple-choice format including finding main idea and identifying supporting details, using text structure to apprehend the meaning from context, analyzing graphic data, gap-fill questions, defining content words, sentence completions, understanding pronoun reference, deducing the meaning of words and phrases from the given alternatives of domain specific vocabulary and composing formal email and business letter. The students' performances were compared using the averages of test scores and percentages of students who passed/failed. The assessment analyzed learners' proficiency in language skills by gauging their level of performance in the tests.

\section{Result}

\subsection{Qualitative analysis}

Table 1. Questionnaire given to course educators

\begin{tabular}{|c|c|c|c|}
\hline Questionnaire 1 & Yes & No & Maybe \\
\hline $\begin{array}{l}\text { 1) Did the coordinator assist course educators in implementing multi- } \\
\text { media in class by clearly communicating how to use UOB Black- } \\
\text { board, Google Docs, and gamification e.g. Kahoot and power point } \\
\text { presentation? }\end{array}$ & $\begin{array}{c}6 \\
86 \%\end{array}$ & $\begin{array}{c}1 \\
14 \%\end{array}$ & \\
\hline $\begin{array}{l}\text { 2) Did the supplementary practice worksheets uploaded on UOB } \\
\text { Blackboard and handouts shared through Google Docs, provide } \\
\text { symmetry in learning material for students? }\end{array}$ & $\begin{array}{c}6 \\
86 \%\end{array}$ & - & $\begin{array}{c}1 \\
14 \%\end{array}$ \\
\hline $\begin{array}{l}\text { 3)Did the use of multimedia enhance the learning environment by } \\
\text { increasing the level of active engagement in class and making learning } \\
\text { fun and interactive? }\end{array}$ & $\begin{array}{c}5 \\
72 \%\end{array}$ & $\begin{array}{c}1 \\
14 \%\end{array}$ & $\begin{array}{c}1 \\
14 \%\end{array}$ \\
\hline $\begin{array}{l}\text { 4) Was the test analysis helpful in identifying the strengths and weak- } \\
\text { ness of students and was a follow up done in improvising the teaching } \\
\text { learning process with the aim of improving students' performance? }\end{array}$ & $\begin{array}{c}6 \\
86 \%\end{array}$ & & $\begin{array}{c}1 \\
14 \%\end{array}$ \\
\hline
\end{tabular}


Based on the questionnaire report and discussions, the information gathered is that the course educators viewed the six ways of implementing technology favorably $(86 \%)$ while a small number remained undecided (14\%) or believed technology did not prove most adequate.

Table 2. Questionnaire given to students

\begin{tabular}{|c|c|c|c|}
\hline Questionnaire 2 & Yes & No & Maybe \\
\hline $\begin{array}{l}\text { Did the use of multimedia in class make learning interactive and } \\
\text { interesting? }\end{array}$ & $\begin{array}{c}31 \\
77.5 \%\end{array}$ & $\begin{array}{c}2 \\
5 \% \\
\end{array}$ & $\begin{array}{c}7 \\
17.5 \% \\
\end{array}$ \\
\hline $\begin{array}{l}\text { Were the supplementary worksheets, PowerPoint presentation on } \\
\text { UOB Blackboard useful? }\end{array}$ & $\begin{array}{c}30 \\
72.5 \%\end{array}$ & $2.5 \%$ & $\begin{array}{c}8 \\
20 \%\end{array}$ \\
\hline
\end{tabular}

The result of the classroom observation of students' performances and the questionnaire given to students it is evident that students perceptions to technological implementation is positive $(77.5 / 72.5 \%)$ whereas a small number were either unsure $(17.5 \% / 20 \%)$ or disagreed. $(5 \% / 2.5 \%)$

Quantitative Analysis

Table 3. Pre-test and Post-test Results

\begin{tabular}{|l|c|c|}
\hline \multicolumn{1}{|c|}{ Total 40 } & Pre Test 1 result (March 2018) & Post test result (May 2018) \\
\hline Pass $(\%)$ & $23(57.5 \%)$ & $32(80 \%)$ \\
\hline Fail $(\%)$ & $17(42.5 \%)$ & $8(20 \%)$ \\
\hline
\end{tabular}

With reference to the experimental evaluation analysis of quantitative data, it is possible to propose that incorporating educational technologies into the teaching learning process had a significant positive impact on students as they boosted students' academic achievement. The mean of the students' performance on the pre-test was 16.8 and on the post-test was $17.38 \%$ Moreover, $80 \%$ of the students passed the post-test whereas only $57.5 \%$ ) passed the pre-test. Digital technologies enhance the engagement of students and promote active learning, build learner autonomy and a love for learning which becomes apparent while assessing their accomplishments. Technology promotes collaborative learning, development of critical thinking and interpersonal skills of students, enables friendly competition and creates a lively classroom dynamic. PowerPoint slideshows grasp attention of learners, make learning fun and enjoyable and help in retention of learnt material. Gamification is very effective for learning active and passive vocabulary. Game based pedagogy helps educators to create the quizzes to reinforce learning outcomes.to determine learners' prior knowledge before presenting any lesson. Using Blackboard and Google Apps assist coordinators in bringing a symmetry of supplementary worksheets among students studying in different sections of a specific course. Implementing educational technologies improves communication with students. It is time saving and reduces pressure caused by course material preparation. The incorporation of educational technologies within teaching enhances learning competencies, and influences teaching effectiveness positively. The positive impact of integrating educational technologies in augmenting the academic accomplishment of the learners and the gamut of teaching and 
learning processes have been proven by many research studies (Rutz et al., (2003), Koedinger, (1999), Baker et al., (1999), Sivin Kachla, (1998).

\section{Discussion}

The study aimed to examine the impact of using digital technologies on the teaching learning performance. The study found that there is a positive impact on students' academic accomplishments. Among the many benefits of using ICT in the English class, the participating educators indicated that it motivates students, by the large variety of resources it offers; students can work at their pace; it caters to diverse learner styles and levels. Using Blackboard improves students' computer literacy skills and helps students to know the course related announcements and access academic material without delay. The online supplementary practice material reinforces taught concepts and the online assessments assist in revision and understanding errors through instant feedback; thus facilitating the teaching learning process. This study is compatible with the former studies (Al-Kandri, (2013); Al-Kadri, (2013) investigating the effectiveness of e-learning in promoting academic achievement. This system saves time as educators may prepare presentations instead of writing manually on white boards. The application of gamification in the pedagogical context promotes motivation and engagement in learning. It provides learners the opportunity to enhance team building skills in friendly competitions while fostering retention of academic material. This positive outcomes in cognitive, emotional, and social areas should also ensure positive effects on performance of students and their scores (Kapp, (2012);Connolly et al., (2012); Ke, (2009); Sitzmann, (2011); in particular, Domínguez et al. (2013) reveal that frequent, meaningful and rapid feedback can improve student results. Lee and Hammer (2011) suggest that gamification develops problem solving skills through a complex system of rules that encourages active exploration and discovery. According to the results of this study multimedia also motivates students emotionally, and socially.Digital multimedia as a teaching and learning aid creates a rich potential for developing cognitive and perceptive capabilities in the learning process. Virtual reality transports the minds of students into a given set of experiences (Losike Sedimo (2003); Seleka, Mgaya, Molemisi, Sechaba, (2006). Learners feel that they are actually experiencing what they were watching on the screen. Such experience has a potential to promote memory of content learned (Kim and Biocca, (1998). This was in line with what (Day, (2003) observed on memory and retrieval. He detailed how multimedia improves cognitive functioning. Online supplementary worksheets and assignments assist students in understanding academic material and preparing for exams as instructors can designed them to provide further practice and reinforcement of areas that learners are having difficulty in. In fact instructors can give students practice on different versions of the same question repeatedly to reinforce learning remarkably. Grading can be quick and easy, with all students' assignments available on one resource. The facility of instant feedback helps learners to rectify their mistakes during the learning process. This promotes students' achievement and class productivity. These online programs prove useful for large sized classes where tradi- 
tional homework are not a suitable option. With its online component, students can no longer pose excuses of forgetting assignments at home. Besides, it is environmental friendly and less paper is wasted in and out of the classroom, all without hindering student learning.

The findings showed that educational technologies facilitate collaborative learning and engagement and this improves the academic performance of students. Hamid et al. (2011) claimed that the use of social media in higher education can be implemented in various ways and lead to fruitful results. While Madge et al. (2009) suggested that by using this technology, educational access and interaction can be improved. Bull et al. (2008) stated that it can also bridge the gap among students and instructors in terms of communication informally. According to (Jones, (1981) the more connected teachers are to their students, the higher are the chances that they are able to help students learn quickly and at a high level. However, educators' role is pivotal in the effectiveness of the implementation of social media, by careful planning, and designing tasks to be accomplished through collaboration on social media and by exercising their authority in maintaining decorum. Fast, easy real time collaboration is encouraging educators to use Google Docs to provide extended practice to learners. This interactive app can be conveniently accessed with any device anytime and anywhere as long as they have internet. Instructors can easily create assessment tests, practice worksheets and questionnaires, store them in the cloud-based storage, and share them with their students by giving the links so they can access the required folder. This encourages self-directed learning as students learn take ownership of their learning. The digital tools augment their understanding. They develop time management skills and learner autonomy. It encourages students to prepare questionnaires and construct knowledge rather than being a passive listener. The pedagogical basis of the OMR system is objective testing. OMR technology system is simple and user-friendly and provides detailed analysis of results which can be used to prepare instructional strategies to enhance students' performances.

\section{Conclusion}

The results of the study reveal that educators can integrate technology for creating very engaging lessons as they can very easily utilize innumerable resources readily accessible online. Before adopting instructional strategies, they can very conveniently prepare online surveys through Google Apps to gather views of learners and colleagues. It is equally easy and fast to get a detailed analysis of the survey results in order to decide on which teaching strategies and teaching learning activities would be appropriate for students. Multimedia implementation in classroom teaching allows for less static and more dynamic learning experiences for students. Gamification as an instructional tool can be adopted to provide more interactive learning experiences, to motivate and engage learners. When students enjoy learning, it paves the way of inculcating the learning process into an ongoing lifelong a habit and gaining learner autonomy. Most higher education institutions envision this attainment as one of their missions. Technology also facilitates assessment of the outcomes of laboriously de- 
signing and conducting lectures by convenient computed test analysis such as OMR which can provide very detailed reports on student performance. Subsequently timely, constructive specific rubric criterion individual feedback can be provided to each learner while doing the learning. This vastly promotes chances of improving and greatly minimizes chances of learners repeating the mistake as they have become aware of what he/she was doing incorrectly. By reflecting on which digital technologies worked well or vice versa or how teaching learning process could be boosted still further, educators would partake in continual professional development and work towards higher teaching learning performances and achievements.

\section{$5 \quad$ Limitations of the Study}

This study is limited by the small sample size used for the purpose. 40 students studying English for Business in Department of English Language \& Literature, College of Arts, during the academic year 2017-18 at University of Bahrain, participated in this study.

\section{$6 \quad$ Recommendation}

Based on the findings, this study recommends that educators should implement educational technologies into the teaching learning process to augment learners' performances. As online assignments significantly impact on student performance, it is recommended this web-based method of collecting assignments can be utilized within the classroom, both for the time-saving environmental benefits. It is also recommended that training in using Blackboard Learn be incorporated into the learning program to facilitate the use of this digital tool among learners. A further research on use of digital technologies can be conducted by comparing students from different faculties in University of Bahrain. It is recommended, at a later stage, to research the progress of students who participated in this study, to attain a clearer perception into their ongoing progression in using digital tools skillfully and to which extend, do their utilization, augment their usage of technology as a lifelong skill. A reflection of these determinants can be of much significance for future researches on technological incorporation in the teaching learning practices.

\section{$7 \quad$ References}

[1] Al-Kadri, S. (2013). The effectiveness of teaching physics online utilizing Blackboard in the achievement of physical concepts among students of Physics Department in the University. Journal of Educational Sciences, 25(1): 179-203.

[2] Al-Kandri, A. (2013).The effectiveness of electronic activities in the achievement and motivation to learning among a sample of Kuwait university students. Educational Journal, 28(109), 13-50. 
[3] Arasasingham, R.D., Martorell, I., \& McIntire, T.M. (2011). Online Homework and Student Achievement in a Large Enrolment Introductory Science Course. Journal of College Science Teaching, 40(6): 70-79.

[4] Atkins-Sayre, W., Hopkins, S., Monhundro, S., \& Sayre, W. (1998) Rewards and liabilities of presentation software as an ancillary tool: Prison or paradise? Paper presented at the annual meeting of the National Communication Association, New York. ERIC Document Reproduction Service No. ED430260

[5] A. Tregobov, "The Web-Based Assignment Submission Systems", presented at NAWeb'98, University of New Brunswick, Canada, (1998).

[6] Berk, R. A. 2009. Multimedia teaching with video clips: TV, movies, YouTube, and $\mathrm{mtvU}$ in the

[7] College classroom. International Journal of Technology in Teaching and Learning, 5(1), 1-21.

[8] Berk, R. A. 2009. Multimedia teaching with video clips: TV, movies, YouTube, and $\mathrm{mtvU}$ in the

[9] Baker, E. L. (1999), "Technology: How do we know it works?", Secretary's Conference on ET, Retrieved May 14, 2002 from http://www.ed.gov/rschstat/eval/ tech/techconf99/whitepapers/paper5.html.IBaker, E.I.,

[10] Bercovici, J., (2010). Who coined "social media"? Web pioneers compete for credit. Retrieved from <http://blogs.forbes.com/jeffbercovici/2018 /12/09/whocoined-social-media-web-pioneers-compete-for-credit/>.

[11] Berk, R. A. (2009). Multimedia teaching with video clips: TV, movies, YouTube, and $\mathrm{mtvU}$ in the college classroom. International Journal of Technology in Teaching and Learning, 5(1), 1-21.

[12] Bransford, J. D., Brown, A. L., \& Cocking, R. R. (1999). How people learn: Brain, mind, experience, and school. Washington, D.C.: National Academy Press.

[13] Bradford, P., Porciello, M., Balkon, N. and Backus D. (2007). The blackboard learning system: The be all and end all in educational instruction? United University Professions. J. Educational Technology systems, 35(3) 301-314. Baywood Publishing Co., Inc. https://doi.org/10.2190/x137-x731-5261-5656

[14] Bouhnik D \& Deshen M (2014) WhatsApp goes to school: Mobile instant messaging between teachers and students Journal of Information Technology Education: Research 13 pp 217-31. https://doi.org/10.28945/2051

[15] Bull, G., Thompson, A., Searson, M., Garofalo, J., Park, J., Young, J., \& Lee, J. (2008). Connecting informal and formal learning experiences in the age of participatory media. Contemporary Issues in Technology and Teacher Education, (2008), 8(2). Retrieved from http://www.citejournal.org/vol8/iss2/editorial/artic le1.cfm [accessed 18 September 2018].

[16] Chen, C. (2017). Eugene Garfield's scholarly impact: A scientometric review. ArXiv preprint arXiv: 1710.01895.

[17] Clark, R. E., \& Feldon, D. F. (2005). Five common but questionable principles of multimedia learning. The Cambridge handbook of multimedia learning. https://doi. org/10.1017/cbo9780511816819.007

[18] Connolly, T.M., Boyle, E.A., MacArthur, E., Hainey, T. and Boyle, J.M. (2012), "A systematic literature review of empirical evidence on computer games and serious games", Computers \& Education, 59,2, 661-686, available at: https://doi.org/ 10.1016/j.compedu.2012.03.004 
[19] Day, (2003). The global; approach to earning. Available. http://www.naledi3d.com/napage.html\%20Accessed:\%20November\%2012,\%202 $\underline{018}$

[20] David Jones, Sandy Behrens, “Online Assignment Management: An Evolutionary Tale," Hawaii International Conference on System Sciences, vol. 5, no. 5, pp. 156c, Track 5, (2003). https://doi.org/10.1109/hicss.2003.1174347

[21] Dominguez, A., Saenz-de-Navarrete, J., de-Marcos, L., Fernandez-Sanz, L., Pages, C., Martinez-Herraiz, J. (2013). Gamifying learning experiences: Practical implications and outcomes. Computers \& Education, 63, 380 - 392. https://doi.org/10. 1016/j.compedu.2012.12.020

[22] DeNeui, D. L. \& Dodge, T. L. (2006). Asynchronous learning networks and student outcomes: the utility of online learning components in hybrid courses. Journal of Instructional Psychology, 33, (4): 256-259.

[23] Dufresne, R., Mestre, J., M. Hart, M. D., \& Rath, K. A. (2002). The effect of web-based homework on test performance in large enrollment introductory physics courses Journal of Computers in Mathematics and Science Teaching, 21(3): 229-251.

[24] Novak, E., Razzouk,R., Johnson,E. (2012), The educational use of social annotation tools in higher education: a literature review Internet High. Educ., 15 (1) 3949. https://doi.org/10.1016/j.iheduc.2011.09.002

[25] Hamid, S., Waycott, J., Kurnia, S., (2011). Appropriating online social networking (OSN) ctivities for higher education: two Malaysian cases. 526-538.

[26] Henn B (2001) Microsoft-Blackboard partnership stirs debate. Dailyprincetonian.com, Dec4.

[27] J. Larusson, J., and Alterman,R., Wikis to support the collaborative part of collaborative learning Int. J. Comput.-Support. Collab. Learn., 4 (2009), 76

[28] Junco, G. Heiberger, E. Loken The effect of Twitter on college student engagement and grades

[29] Comput,J., Assist. Learn., (2011), 27 (2): 119-132

[30] Kapp, K.M. (2012), "Games, gamification, and the quest for learner engagement", Training and Development, 66 (6): 64-68.

[31] Koedinger, K. and Anderson, J (1999), PUMP algebra project: AI and high school math, Pittsburgh, PA: Carnegie Mellon University, Human-Computer Interaction institute, http://act.psy.cmu.edu/awpt/awpt-home.html

[32] Ke F. (2009), A Qualitative Meta-Analysis of Computer Games as Learning Tools, in: Ferdig R.E. (Ed.), Effective Electronic Gaming in Education (pp. 1-32). Hershey, Information Science Reference. https://doi.org/10.4018/978-1-59904-808-6. $\underline{\mathrm{ch} 001}$

[33] Kim, T., \& Biocca, F. (1997). Telepresence via television: Two dimensions of telepresence may have different connections to memory and persuasion. Journal of Computer-Mediated Communication, 3(2). https://doi.org/10.1111/j.1083-6101.19 97.tb00073.x

[34] Lee, J.J. and Hammer, J. (2011), "Gamification in education: what, how, why bother?" Academic Exchange Quarterly, 15 (2): 1-5.

[35] Madge, C., Meek, J., Wellens, J., and Hooley, T. (2009). Facebook, social integration and informal learning at university: It is more for socialising and talking 
to friends about work than for actually doing work. Learning, Media and Technology, 34(2): 141-155. https://doi.org/10.1080/17439880902923606

[36] Mansour, E (2012). The role of social networking sites (SNSs) in the January 25th Revolution in Egypt. Library Review 61(2): 128-159. https://doi.org/10.1108/0 $\underline{0242531211220753}$

[37] McFarlane, A., Sparrowhawk, A., \& Heald, Y. (2002). Report on the educational use of games. Retrieved 18 September 2018 from http://www.teem.org.uk/publica tions/teem_gamesined_full.pdf

[38] Ogilve, C. (2000). Effectiveness of different course components in driving gains in conceptual understanding, Cambridge, Internal report, Department of Physics at MIT [online] URL: http://torrseal.mit.edu/effedtech

[39] Papastergiou, M. (2009). Digital game-based learning in high school computer science education: Impact on educational effectiveness and student motivation. Computers \& Education, 52(1): 1-12. https://doi.org/10.1016/j.compedu.2008.06.004

[40] Educ. Tech. Res. Develop., 59 (2) (2011), 213-228

[41] Rouse, M., \& Wigmor, I. (2015). Social Media. In What is. Retrieved 2015-10-10

[42] Ringstaff, C \& Kelly, L. (2002). The learning return on our educational technology investment: A review of findings from research. San Fransico, CA: WestEd RTEC

[43] Rouse, M., \& Wigmor, I. (2015). Social Media. In What is. Retrieved 2015-10-18 from http://whatis.techtarget.com/definition/social-media

[44] Rutz, Eugene; Eckart, Roy; Wade, James; Maltbie, Virginia (2003), "Student performance and acceptance of instructional teaching: Comparing technology- enhanced and traditional instruction for a course in STATICS", Journal of Engineering Educational, 92, ( 2). https://doi.org/10.1002/j.2168-9830.2003.tb00751.x

[45] Seleka, G. G. Mgaya, K. V., Molemisi, N., Sechaba. The use of various ICTs in blended Collaborative learning at the University of Botswana. Available: http://emerge2006.net Retrieved October, 2018.

[46] Sivin-Kachala, J. (1998), Report in the effectiveness of technology in school, 1990-1997. Software Publishers Association U.S. Congress, Office of Technology Assessment, Power On! New Tools for Teaching and Learning, OTA-SET379 (Washington, D.C.: U.S. GPO, Sept. 1988).

[47] Sitzmann, T. (2011), 'A meta-analytic examination of instructional effectiveness of computer-based simulation games', Personnel Psychology, 64:489-528. https:// doi.org/10.1111/j.1744-6570.2011.01190.x

[48] Thoennessen, M., and Harrison, M. (1996). Computer-assisted assignments in a large physics class. Computers Education, 27(2): 141-147. https://doi.org/10.1016/ 0360-1315(96)00003-6

[49] Tregobov.A, (1998). The Web-Based Assignment Submission Systems. presented at NAWeb'98, University of NewBrunswick, Canada

[50] Rouse, M., \& Wigmor, I. (2015). Social Media. In What is. Retrieved 2015-10-10 from http://whatis.techtarget.com/definition/social-media 


\section{Author}

Preeti Jaiswal is a lecturer and Coordinator at the English Language Centre, University of Bahrain. She is Senior Fellow (SFHEA) of Advance HE, Higher Education Academy, United Kingdom. She is a member of the Unit for Teaching Excellence and Leadership (UTEL) at the University of Bahrain (UoB), and mentor of UTEL's faculty development programs, namely the Continuous Professional Development (CPD) program of Advance HE, Higher Education Academy, United Kingdom. She has an MA in English literature from Delhi University, India and has completed CELTA and TESOL. She has twenty-three years' experience of teaching ESL, ESP and EAP courses at University level. Since 2011, she has been teaching at University of Bahrain. In May 2004, she was awarded Certificate of Appreciation by the Chairman, Department of English, Arts Faculty in Garyounis University. In June 2018, she received the Teaching Excellence Award and Professional Development award by the Director, English Language Centre, University of Bahrain.

Article submitted 2019-10-02. Resubmitted 2019-11-18. Final acceptance 2019-11-19. Final version published as submitted by the authors. 